Article

\title{
Lipidomic Profiling Reveals Distinct Differences in Sphingolipids Metabolic Pathway between Healthy Apis cerana cerana larvae and Chinese Sacbrood Disease
}

\author{
Xiaoqun Dang ${ }^{1}$, Yan Li ${ }^{1}$, Xiaoqing Li ${ }^{1}$, Chengcheng Wang ${ }^{1}$, Zhengang Ma ${ }^{1}$, Linling Wang ${ }^{1}$, Xiaodong Fan ${ }^{1}$, \\ Zhi Li ${ }^{1}$, Dunyuan Huang ${ }^{1}$, Jinshan $\mathrm{Xu}^{1, * \mathbb{D}}$ and Zeyang Zhou ${ }^{1,2,3, *}$
}

1 Chongqing Key Laboratory of Vector Insect, College of Life Science, Chongqing Normal University, Chongqing 401331, China; 20132103@cqnu.edu.cn (X.D.); 2018110513030@stu.cqnu.edu.cn (Y.L.); 2019110513029@stu.cqnu.edu.cn (X.L.); 2020110513043@stu.cqnu.edu.cn (C.W.); 20140003@cqnu.edu.cn (Z.M.); 20130776@cqnu.edu.cn (L.W.); fanxd@cqnu.edu.cn (X.F.); lizhi@cqnu.edu.cn (Z.L.); 20170054@cqnu.edu.cn (D.H.)

2 State Key Laboratory of Silkworm Genome Biology, College of Biotechnology, Southwest University, Chongqing 400715, China

3 Chongqing Key Laboratory of Microsporidia Infection and Control, Southwest University, Chongqing 400715, China

* Correspondence: xujinshan2008@cqnu.edu.cn (J.X.); zyzhou@cqnu.edu.cn (Z.Z.)

\section{check for}

updates

Citation: Dang, X.; Li, Y.; Li, X.; Wang, C.; Ma, Z.; Wang, L.; Fan, X.; Li, Z.; Huang, D.; Xu, J.; et al. Lipidomic Profiling Reveals Distinct Differences in Sphingolipids Metabolic Pathway between Healthy Apis cerana cerana larvae and Chinese Sacbrood Disease. Insects 2021, 12, 703. https:// doi.org/10.3390/insects12080703

Academic Editor:

Raquel Martín-Hernández

Received: 12 July 2021

Accepted: 3 August 2021

Published: 5 August 2021

Publisher's Note: MDPI stays neutral with regard to jurisdictional claims in published maps and institutional affiliations.

Copyright: (c) 2021 by the authors. Licensee MDPI, Basel, Switzerland. This article is an open access article distributed under the terms and conditions of the Creative Commons Attribution (CC BY) license (https:/ / creativecommons.org/licenses/by/ $4.0 /)$.
Simple Summary: Chinese Sacbrood Virus (CSBV) is one of the most destructive viruses; it causes Chinese sacbrood disease (CSD) in Apis cerana cerana, resulting in heavy economic loss. In this study, the first comprehensive analysis of the lipidome of A. c. cerana larvae-infected CSBV was performed. Viruses rely on host metabolites to infect, replicate and disseminate from several tissues. The metabolic environments play crucial roles in these processes amplification and reproduction processes. Using high-resolution mass spectrometry, we profiled 2164 lipids in larva samples obtained from healthy controls and larvae with CSBV infection. A total of 266 lipids, including categories of DG, TG, PC, PE, SM and Cer, were significantly changed after CSBV infection, considering that qRT-PCR showed that seven sphingolipid enzymes involved in the sphingolipid pathway were increased. This suggests that the lipidome of honeybee larvae is altered in CSBV infection, and sphingolipids may contribute to CSD progression. Specific changes in the lipidome such as TG (39:6), which showed a more than 10-fold increase, may be possible targets for the detection of CSD. Lipid pathways analyses revealed that glycerophospholipid metabolism was the most enriched pathway and may be associated with CSBV infection.

Abstract: Chinese sacbrood disease (CSD), which is caused by Chinese sacbrood virus (CSBV), is a major viral disease in Apis cerana cerana larvae. Analysis of lipid composition is critical to the study of CSBV replication. The host lipidome profiling during CSBV infection has not been conducted. This paper identified the lipidome of the CSBV-larvae interaction through high-resolution mass spectrometry. A total of 2164 lipids were detected and divided into 20 categories. Comparison of lipidome between healthy and CSBV infected-larvae showed that 266 lipid species were altered by CSBV infection. Furthermore, qRT-PCR showed that various sphingolipid enzymes and the contents of sphingolipids in the larvae were increased, indicating that sphingolipids may be important for CSBV infection. Importantly, Cer (d14:1 + hO/21:0 + O), DG (41:0e), PE (18:0e/18:3), SM (d20:0/19:1), SM (d37:1), TG (16:0/18:1/18:3), TG (18:1/20:4/21:0) and TG (43:7) were significantly altered in both CSBV_24 h vs. CK_24 h and CSBV_48 h vs. CK_48 h. Moreover, TG (39:6), which was increased by more than 10-fold, could be used as a biomarker for the early detection of CSD. This study provides evidence that global lipidome homeostasis in A. c. cerana larvae is remodeled after CSBV infection. Detailed studies in the future may improve the understanding of the relationship between the sphingolipid pathway and CSBV replication.

Keywords: Chinese sacbrood virus; A. cerana cerana larva; lipidomics; glycerolipids; sphingolipid 


\section{Introduction}

Apis mellifera and Apis cerana cerana, which are required for agricultural production and nutrient-rich beehive products, are increasingly grown in China [1]. However, over the last few decades, honeybee populations have been found to often die or escape because of infection with pathogens such as viruses, bacteria, fungi, parasites and protozoa [2,3]. Sacbrood virus (SBV) is distributed worldwide and is the first honeybee virus identified by Bailey [4,5]. Infection by SBV is lethal to honeybee larvae, which results in entire colony collapse for A. c. cerana, while A. mellifera-infected colonies rarely collapse [6,7]. Thus, the Chinese sacbrood virus (CSBV) is the most serious threat to A. c. cerana health. Currently, CSBV is widespread in China and Southeast Asia worldwide [8].

CSBV mainly infects 1- to 3-day-old larvae of A. c. cerana by breeding and results in larval death and reduces the lifespan of adult bees [6]. Symptoms of CSBV infection include ecdysial fluid accumulation, cuticle discoloration and formation of "larvae sac" before death [9]. CSBV has a positive-sense single-stranded RNA genome and is a typical member of the genus Iflavirus, the family Iflaviridae and the order Picornavirales [10]. The genome encodes a single 2858-aa-long polyprotein that is cotranslationally and posttranslationally cleaved by viral proteases into functional protein subunits. To date, three iflaviruses have been structurally characterized: slow bee paralysis virus (SBPV), deformed wing virus (DWV) and SBV [11-13]. The structural analysis of SBV showed that the pore of an empty virion particle expands at $\mathrm{pH} 5.8$ compared with the pore of full virion at $\mathrm{pH} 7.4$ (12 ̊ vs. $7 \AA$ in diameter), and subsequently, the genome is released [14].

RNA viruses need host factors to support their replication, and host lipid components are necessary. It is reported that (+) RNA viruses remodel lipid metabolism through coordinated virus-host interactions to create a suitable microenvironment to survive and thrive in host cells [15]. For example, the Hepatitis C virus (HCV) life cycle is tightly linked to the host cell lipid metabolism [16,17]. HCV-infected cells accumulate cholesterol, phospholipids and polyunsaturated fatty acids. Host lipidome analysis during rhinovirus replication showed increased fatty acid elongation and desaturation [18]. Serum lipidome analysis after Zika virus (ZIKV) infection demonstrated an increase in several phosphatidylethanolamine (PE) lipid species, suggesting a link between ZIKV life cycle and peroxisomes [19]. Dengue virus (DENV) is an arbovirus transmitted by mosquitoes, such as Aedes aegypti and Aedes albopictus. The midgut metabolomics of $A$. aegypti infected with DENV revealed that glycerophospholipids, sphingolipids and fatty acyls were coincident with the kinetics of viral replication $[20,21]$. Collectively, these data demonstrate that lipids play critical roles in viral infection.

Although lipid biochemistry has been studied in insects for several years, whether the host lipids regulate CSBV replication remains unknown. Thus, identification and analysis of lipid components of the host are important for the investigation of the molecular mechanism of CSBV replication. In this study, we used high-resolution mass spectrometry to explore metabolic changes in the larvae of A. c. cerana exposed to CSBV-containing foods. Using a time-course study, we compared lipid profiles of infected and uninfected larvae at $24 \mathrm{~h}$ and $48 \mathrm{~h}$ post-infection (peak viral replication). Specific lipids, including diacylglycerol, triglycerides and ceramide, after virus infection were identified, which represented the lipid species that were regulated by CSBV infection. Furthermore, qRT-PCR analysis revealed that sphingolipid was the most perturbed pathway after CSBV infection.

\section{Materials and Methods}

\subsection{Sample Collection}

For virus purification, the 5th-instar larvae with CSBV infection were collected and placed in sterile PBS. Following the methodology described by Feng et al. [22], CSBV was purified and filtered through a $0.22 \mu \mathrm{m}$ cell filter and stored at $-80^{\circ} \mathrm{C}$. Subsequently, we collected larvae from colonies and transferred them to 24-well plate. The larvae were then reared in an incubator at $34 \pm 1{ }^{\circ} \mathrm{C}$ and $90 \% \pm 5 \%$ relative humidity as previously described [23]. After $12 \mathrm{~h}$ incubation, the purified CSBV was fed to 2-day-old A. c. cerana 
larvae with $2 \times 10^{5}$ copies. For each treatment-sampling time point, one group of 5-6 larvae were collected and washed with DEPC water and put into a $0.5 \mathrm{~mL}$ microfuge tube, then immediately flash-frozen in liquid nitrogen and stored at $-80^{\circ} \mathrm{C}$ for lipidomics analysis. Each experiment was repeated 3 times. The rest samples were used for qRT-PCR analysis.

\subsection{Lipidomics}

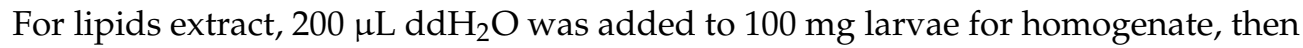
$240 \mu \mathrm{L}$ pre-cooled methanol was added and dissolved, after which $800 \mu \mathrm{L}$ MTBE was added for mixing. The mixture was subjected to ultrasonic in $4{ }^{\circ} \mathrm{C}$ water bath for $20 \mathrm{~min}$ and incubated at room temperature for $30 \mathrm{~min}$. Last, the upper organic phase was obtained by $14,000 \times g$ centrifugation $15 \mathrm{~min}$ at $10^{\circ} \mathrm{C}$ and dried with the protection of nitrogen blowing. Before mass spectrometry analysis, the solid residue was re-dissolved with $200 \mu \mathrm{L}$ $90 \%$ isopropyl alcohol/acetylene solution and then centrifuged at $14,000 \times \mathrm{g}$ for $15 \mathrm{~min}$ at $10^{\circ} \mathrm{C}$. The supernatants were used for UPLC-Q-Orbitrap MS analysis. Before lipidomics analysis, quality control samples $(\mathrm{QC})$ were prepared by taking equal amounts of samples from each group and mixing them for QC. QC samples were used to determine the state of the instrument before injection and balance the chromatography-mass spectrometry system, and then they were used to evaluate the stability of the system throughout the experiment.

Samples were isolated using the UHPLC Nexera LC-30A ultra-efficient liquid chromatography system. The column was maintained at a temperature of $45^{\circ} \mathrm{C}$ and eluted at a flow rate of $0.3 \mathrm{~mL} / \mathrm{min}$. The injection volume was $3 \mathrm{uL}$. The mobile phase was composed of A (6:4 acetonitrile:water, with $10 \mathrm{mM}$ ammonium acetate) and B (1:9 acetonitrile:isopropanol, with $10 \mathrm{mM}$ ammonium acetate) with a linear gradient elution: 0-2 $\mathrm{min}$, $30 \% \mathrm{~B} ; 2-25 \mathrm{~min}, 30-100 \% \mathrm{~B} ; 25-30 \mathrm{~min}, 30 \% \mathrm{~B}$. Lipid extracts were subjected to mass spectrometric analysis using a $Q$ Exactive mass spectrometer (Thermo Fisher Scientific, Waltham, MA, USA) equipped with a TriVersa NanoMate (Advion Biosciences, Ithaca, NY, USA). The source parameters were set as follows: capillary voltage $3.00 \mathrm{KV}$ for ESI+ and $2.50 \mathrm{KV}$ for ESI-, (other parameters of both positive and negative ions were the same) source temperature $300^{\circ} \mathrm{C}$. The acquisition cycle consisted of FT MS and FT MS/MS scans in positive and negative ion mode. FT MS spectra were acquired at the mass resolution of $\mathrm{Rm} / \mathrm{z} 200=70,000$, and FT MS/MS spectra were acquired at the mass resolution of $\mathrm{Rm} / \mathrm{z} 200=17,500$.

\subsection{Data Processing, Lipid Identification and Quantification}

Lipid species detected by high-resolution FT MS and FT MS/MS analysis with LipidSearch software version 4.1 (Thermo ${ }^{\mathrm{TM}}$ ) (Thermo Science, Waltham, MA, USA) and quantified using Excel-based calculation. In short, the main parameters were as follows: precursor tolerance, $5 \mathrm{ppm}$; product tolerance, $5 \mathrm{ppm}$; product ion threshold, $5 \%$. Then, the data matrix was imported to the SIMCA-P 14.1 software package (Umetrics, Umea, Sweden) to conduct unsupervised component analysis (principal component analysis PCA), partial least-squares-discriminant analysis (PLS-DA) and orthogonal partial least-squaresdiscriminant analysis (OPLS-DA). Combined student T test, Fold Change Analysis (FC) and the variable importance in projection (VIP), which reflects both the loading weights for each component and the variability of the response explained by this component, were used to find the potential markers in the infected group. ( $\mid \log 2$ fold change $\mid)>1$ and $p$-value $<0.05$ were used to screen the different lipids features among different groups.

\subsection{Statistical Analysis}

Data were expressed at the form of means \pm SD. Univariate statistical analysis was performed using SPSS (version 19). Data were analyzed using an independent $t$-test. $p$-values $<0.05$ were considered statistically significant. 


\subsection{Quantitative Real-Time PCR}

To investigate CSBV proliferation in A. cerana cerana larvae, the specific primer pair of the CSBV VP1 gene was designed. The primers for sphingolipid pathway-related enzymes used in quantitative RT-PCR (qPCR) were also designed based on their sequences, downloaded from NCBI (Table 1). Total RNAs were extracted with Trizol, and cDNA was acquired by EvoScript Universal cDNA (Cat No. 07912374001, Roche, Mannheim, Germany). The qPCR reaction was performed in Bio-Rad CFX96 real-time system (Bio-Rad, Hercules, CA, USA) using FastStart essential DNA Green Master (Cat No. 06402712001, Roche) according to the instructions from the manufacturer. Briefly, $10 \mathrm{ng}$ of cDNA, $10 \mu \mathrm{L}$ Master mix $2 \times$ conc, $0.5 \mu \mathrm{L}$ of each primer and $\mathrm{ddH}_{2} \mathrm{O}$ were added to make a $20 \mu \mathrm{L}$ reaction, and PCR was performed under the following conditions: denaturation at $95^{\circ} \mathrm{C}$ for $30 \mathrm{~s}$, 30 cycles of $95{ }^{\circ} \mathrm{C}$ for $5 \mathrm{~s}, 55^{\circ} \mathrm{C}$ for $30 \mathrm{~s}$ and $72{ }^{\circ} \mathrm{C}$ for $50 \mathrm{~s}$. The actin gene of A. c. cerana was used as an internal gene to normalize the target gene expression and to correct the variation of sample-to-sample. The relative expression levels of sphingolipid enzymes and CSBV VP1 were calculated based on the relative quantitative method (2- $\Delta \Delta t)$. To detect the copy number of CSBV, VP1 was cloned into vector pMD19T, and the constructed standard plasmid was detected for $\mathrm{Ct}$ value of copy number by real-time fluorescence quantitative PCR and then a standard curve of virus copy number against $\mathrm{Ct}$ was plotted, and the corresponding equation was obtained Statistical analyses were performed using the GraphPad Prism8 software (https:/ / www.graphpad.com/scientific-software/prism/, accessed on 11 November 2019). A two-way analysis of variance with a least significant difference test was applied to compare differences in gene expression among multisamples. The level of significant difference was set at $p<0.05$.

Table 1. Primers used in reverse transcription PCR and quantitative RT-PCR.

\begin{tabular}{|c|c|c|c|c|}
\hline Name & Aberration & Accession No. & Primer & Sequence $\left(5^{\prime}-3^{\prime}\right)$ \\
\hline \multirow{2}{*}{ phospholipase B1 } & \multirow{2}{*}{ AcPLB1 } & \multirow{2}{*}{ XM_017059237.2 } & $\mathrm{F}$ & TTGACTGACAATGGATATTATG \\
\hline & & & $\mathrm{R}$ & GTCTTTCAGAAGTAGGACACAA \\
\hline \multirow{2}{*}{ serine palmitoyltransferase 1} & \multirow{2}{*}{ AcSPT1 } & \multirow{2}{*}{ XM_017049187.1 } & $\mathrm{F}$ & AAGGATTGGATGCAACTAAAGC \\
\hline & & & $\mathrm{R}$ & CTGGTAATGGACAGATATTTCCAG \\
\hline \multirow{2}{*}{ Ceramide synthase5 } & \multirow{2}{*}{ AcCS5 } & \multirow{2}{*}{ XM_017049042.1 } & $\mathrm{F}$ & AATAGTGCCTATGTTCCCAGCA \\
\hline & & & $\mathrm{R}$ & ATCCTCACTGCTACTACTACGA \\
\hline \multirow{2}{*}{ Ceramidase } & \multirow{2}{*}{ AcCeramidase } & \multirow{2}{*}{ XM_017052678.1 } & $\mathrm{F}$ & GCACAACGGTTACTATCGTTAC \\
\hline & & & $\mathrm{R}$ & CATGTAGCTATATATTAAGGAG \\
\hline \multirow{2}{*}{ Sphingomyelinase } & \multirow{2}{*}{ AcSMase } & \multirow{2}{*}{ XM_017050328.1 } & $\mathrm{F}$ & GTGGAGTTATTGGATCTGGACT \\
\hline & & & $\mathrm{R}$ & TTGAAGTTTACAAAGTCCGACA \\
\hline \multirow{2}{*}{$\begin{array}{c}\text { sphingomyelin } \\
\text { phosphodiesterase }\end{array}$} & \multirow[b]{2}{*}{ AcSMPD } & \multirow[b]{2}{*}{ XM_017055261.1 } & $\mathrm{F}$ & CCGTTATGCTGCAGATTGACAA \\
\hline & & & $\mathrm{R}$ & GAGCATATGTTCAACGGTTCTC \\
\hline \multirow{2}{*}{$\begin{array}{c}\text { sphingomyelin } \\
\text { phosphodiesterase } 1\end{array}$} & \multirow{2}{*}{ AcSMPD1 } & \multirow{2}{*}{ XM_017060020.1 } & $\mathrm{F}$ & GGAATGGTGGTAGCATAACAGC \\
\hline & & & $\mathrm{R}$ & TTTGCTGCTATAGAGAGCCAAT \\
\hline \multirow{2}{*}{$\begin{array}{c}\text { sphingomyelin } \\
\text { phosphodiesterase } 4\end{array}$} & \multirow{2}{*}{ AcSMPD4 } & \multirow{2}{*}{ XM_017064091.1 } & $\mathrm{F}$ & ATGAGGACAGATCTTGTAGCCC \\
\hline & & & $\mathrm{R}$ & CGTACAATTGAAGCCCATTGAT \\
\hline \multirow{2}{*}{ glucosylceramidase-like } & \multirow{2}{*}{ AcGSC } & \multirow{2}{*}{ XM_017065397.1 } & $\mathrm{F}$ & ATTTAAGATTCTTTAGCGCCGC \\
\hline & & & $\mathrm{R}$ & GAATGGCTCGTTTCCAGTTGAA \\
\hline \multirow{2}{*}{ glucosylceramidase 4} & \multirow{2}{*}{ AcGSC4 } & \multirow{2}{*}{ XM_017065381.1 } & $\mathrm{F}$ & TCCACCGATTTTTCTACGAGAA \\
\hline & & & $\mathrm{R}$ & GCTGCGAACAATAGTACTTCAG \\
\hline \multirow{2}{*}{ Sacbrood virus CSBV-LN } & \multirow{2}{*}{$\mathrm{qVp} 1$} & \multirow{2}{*}{ gi|307148859| } & $\mathrm{F}$ & TAGAGTTACGTTTTGATTTTGTTT \\
\hline & & & $\mathrm{R}$ & GCGCTAGCCGTATTTCTC \\
\hline
\end{tabular}




\section{Results and Discussion}

\subsection{General Description of Lipidome Data}

The morphology of CSBV-infected larvae displayed a change in body color from white to light yellow. In addition, the infected body was swollen with ecdysial fluid accumulation under the transparent epidermis (Figure 1A,B). Subsequently, individual groups were tested for CSBV VP1 by qRT-PCR (Figure 1C) after samples were collected to estimate virus infection per group. The relative transcript level of VP1 was undetectable in healthy larvae. In contrast, a significant increase in the virions was found at $12 \mathrm{~h}, 24 \mathrm{~h}$ and $48 \mathrm{~h}$ post-infection. Both the symptoms of CSD and the copies of CSBV indicated that the lipidome profile of the larvae could represent the infected state.
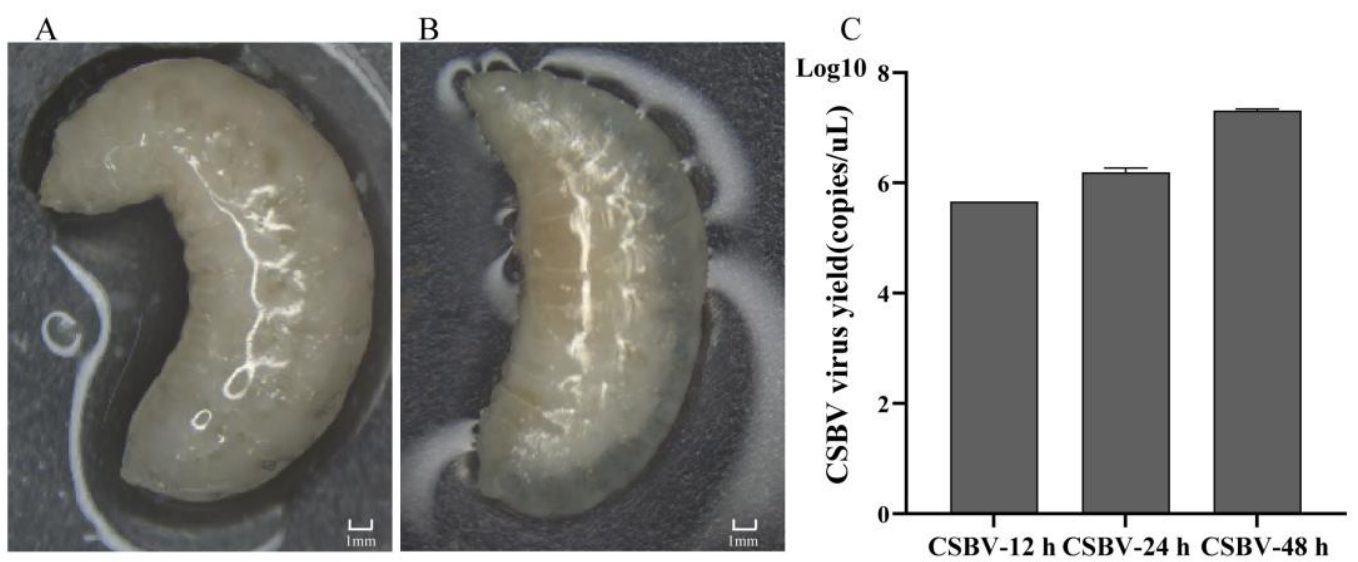

Figure 1. Morphological characteristics of CSBV-infected larvae and relative quantification analysis of CSBV at each time point after larvae infection. The CSBV-infected larva (B) was swollen and smaller compared with the healthy larvae of $A$. $c$. cerana (A). (C) The copies of the CSBV virus.

The lipids extracted from each time point infected larvae were subjected to both negative and positive electrospray ionization modes to obtain the most comprehensive coverage. After pareto scaling, the peaks extracted from all the experimental samples and QC samples were analyzed by PCA. As shown in Figure 2A, QC samples were clustered in the middle of each group, which indicated that the experiment had good repeatability. The PCA model parameters were obtained by cross-validation (seven cycles of interactive verification). The obtained lipid profile differences reflect the biological differences between CSBV infection and healthy larvae. Partial least squares discrimination analysis (PLSDA) was used to visually discriminate between CSBV-infected larvae and healthy controls. As shown in Figure 2B, CSBV-infected groups (CSBV_24 $\mathrm{h}$ and CSBV_48 h) could be reliably discriminated from healthy controls.

For all the samples, a total of 2164 molecular features from all modes and time points post-infection were detected (Figure 3A). These features were subjected to statistical analysis to compare the differences in metabolite abundance between CSBV-infected and uninfected at each time point post-infection. A total of 266 features that showed statistically significant differences in abundance were identified using LIPID MAPS databases. These 266 lipid molecular species were distributed into ceramide (Cer), lysophosphatidylcholine (LPC), lysophosphatidylethanolamine (LPE), lysophosphatidylglycerol (LPG), monoglyceride (MG), phosphatidate (PA), phosphatidylcholine (PC), phosphatidylethanolamine (PE), diglyceride (DG), phosphatidylglycerol (PG), phosphatidylinositol (PI), phosphatidylserine (PS), sphingomyelin (SM), sphingolipids (So), triglyceride (TG) and (O-acyl)-1-hydroxy fatty acid (OAHFA) (Figure 3A). Among the features with altered levels, 75 and 191 features showed differential abundance at $24 \mathrm{~h}$ and $48 \mathrm{~h}$ post-infection, respectively, whereas 10 features showed differential abundance at both $24 \mathrm{~h}$ and $48 \mathrm{~h}$ post-infection (Figure 3B). 

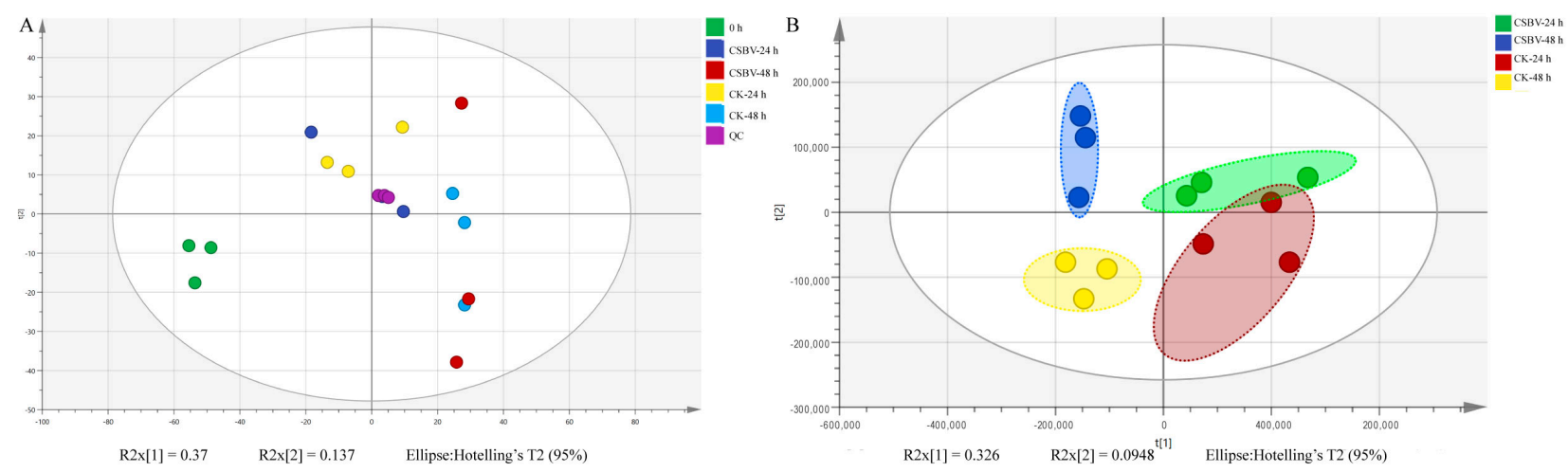

Figure 2. Score plots obtained from PCA (A) and PLSDA (B) analysis of the present lipidomics data in both CSBV-infected and healthy larvae.

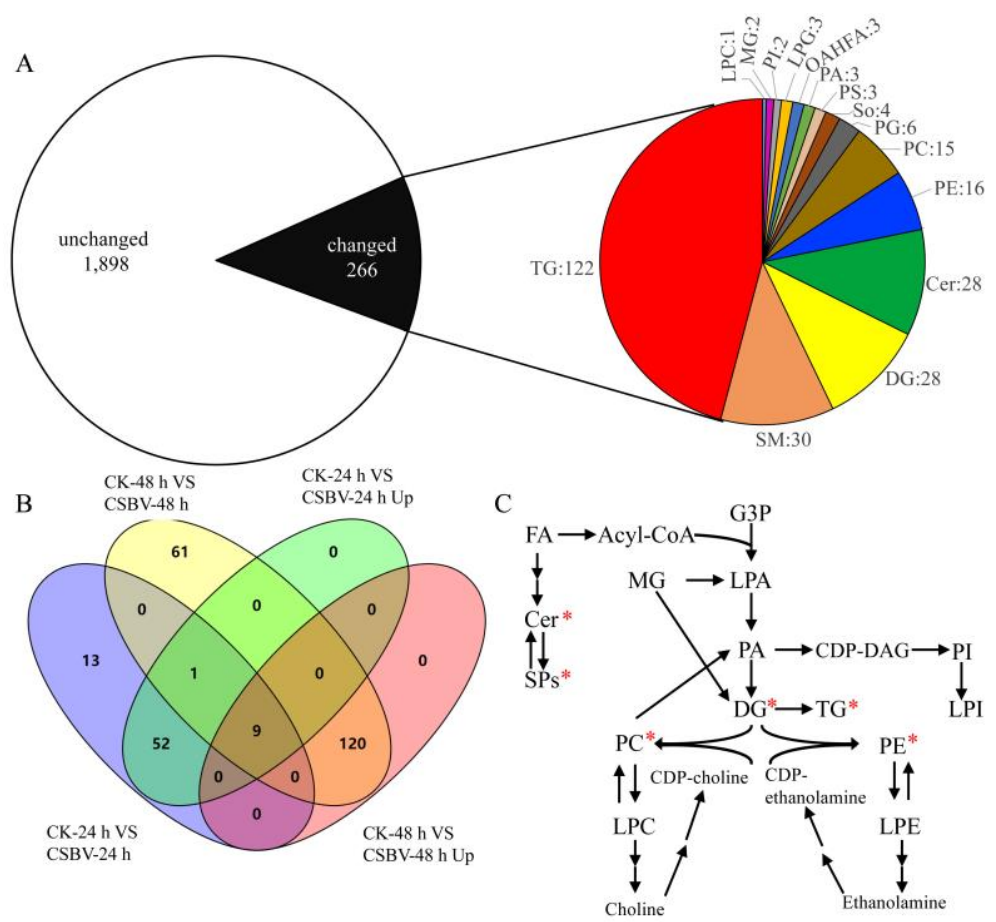

Figure 3. Lipidomics profile of the A.c. cerana larvae during the course of CSBV infection significant changes were observed in the metabolic profile of the larvae upon infection. (A) The right pie chart displays the total lipids identified in this study, the left pie chart shows numbers of features in the larvae detected on $24 \mathrm{~h}$ and $48 \mathrm{~h}$ following a CSBV-infectious compared to the health larvae with significantly altered levels of abundance ( $\mid \log 2$ fold change $\mid>1$ and $p$-value $<0.05)$ in black and non-significantly altered levels of abundance ( $\mid \log 2$ fold change $\mid<1$ or $p$-value $>0.05$ ) in white. The right pie chart displays the distribution of the changed lipids. (B) The Venn diagram shows numbers of features that were altered in abundance in CSBV-infected larvae compared to uninfected larvae. (C) Overview of lipid classes observed in this study and their relationships to each other within metabolic pathways. Red stars ${ }^{* \prime}$ indicate that the lipids were significantly changed in lipid levels.

The majority of the metabolites were unchanged (with $<1$-fold intensity changes upon infection, $p>0.05$ ). In addition, about $12 \%$ of features (266 out of 2164 ) with differential abundance were identified using three metabolite databases, and the putative identifications were categorized into different metabolite classes. The overall trend of lipid molecular levels that changed upon CSBV infection is summarized in Figure 3C, while the majority of those (182 out of 266 features) that showed greater than 1-fold changes in intensity had 
higher abundances upon CSBV infection (Figure 3B). Only 28.6\% of lipid species decreased in abundance during CSBV infection.

To observe the discrimination trend in more detail, a hierarchical clustering analysis was performed based on the degree of similarity of lipid abundance profiles to show the overall trend of all significant ion features. As indicated in Figure 4, most of the significant features expressed an up-regulation trend after both $24 \mathrm{~h}$ (Figure $4 \mathrm{~A}$ ) and $48 \mathrm{~h}$ post-infection (Figure 4B) compared with the healthy larvae. Moreover, the larvae of A. c. cerana are so small that there were inevitable differences in the three repeats because of the individual differences. Further study will focus on midguts, which is the main infection site.

A

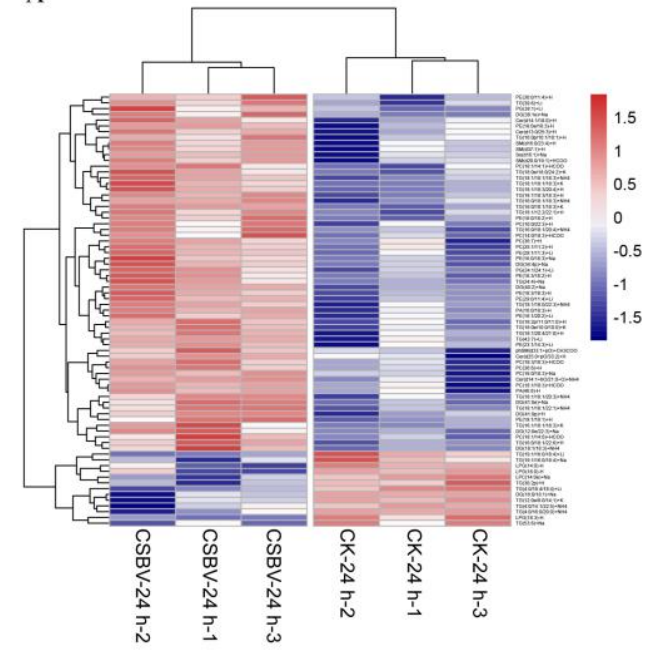

B

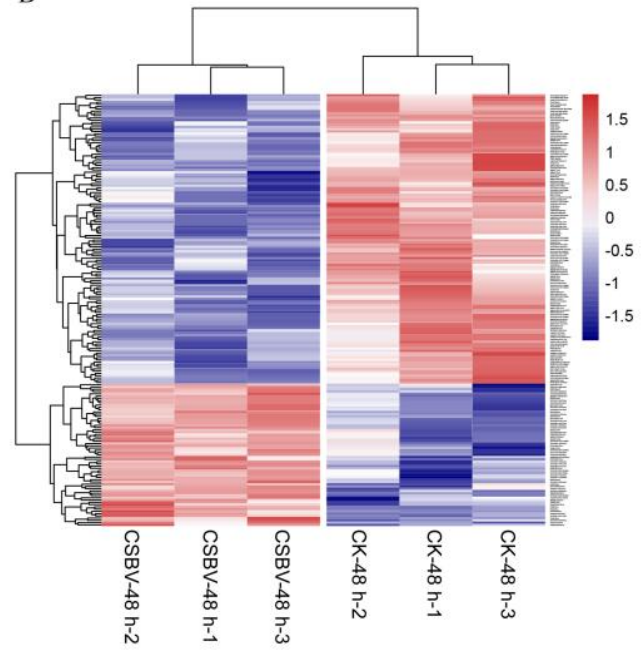

Figure 4. Global lipidome profile of CSBV-infected versus uninfected A. c. cerana larvae. (A) Heatmap showing the lipidomic analysis of CSBV_24 h vs. CK_24 h; (B) heatmap showing the lipidome analysis of CSBV_48 h vs. CK_48 h.

\subsection{Glycerolipids Showed Maximal Remodeling after CSBV Infection}

To gain insight into the lipid metabolic reprogramming of the larvae during CSBVinfection, we first analyzed the glycerolipids (GP) profile during viral replication in comparison to uninfected larvae, which were majorly altered (about 180 of 266). GPs, such as mono-, di- and triacylglycerols (MG, DG and TG), are critical effectors of energy metabolism in insects and mammals. DG is a critical second messenger regulating cell proliferation, survival, mitochondrial physiology, gene expression and apoptosis [24,25]. TG containing a glycerol backbone and three fatty acyl chains has a high energy content. Most of the DG and TG levels of CSBV-infected larvae were higher than those of healthy larvae (Figure 5C). A total of 122 species of TGs were identified in this study, of which 113 TGs were significantly changed in abundance upon infection (Figure 5). Moreover, 72 species of TG levels were higher during the early stage (24 hpi) in the CSBV-infected larvae, indicating that TGs may serve as storage molecules, induced by the virus as an energy and lipid pool to support the demand for viral replication [26,27]. HCV is known to promote the mobilization and recruitment of lipid droplets responsible for the cellular stock of TGs [28,29]. In addition, phospholipase B1 (PLB1) acts as a hydrolyzed enzyme, which can remove fatty acids from phospholipids and hemolytic phospholipids [30]. qRT-PCR showed that AcPLB1 was significantly increased by nine times at $24 \mathrm{~h}$ post-CSBV infection (Figure 5D), presumably causing glycerophospholipid degradation, which may contribute to the accumulation of DG and TG. GPs are critical effectors of energy metabolism in insects and mammals. Given that the transcriptional level of AcPLB1 was up-regulated, CSBV infection may cause a higher level of lipolysis. The precise role of the increased TG accumulation needs to be explored. 


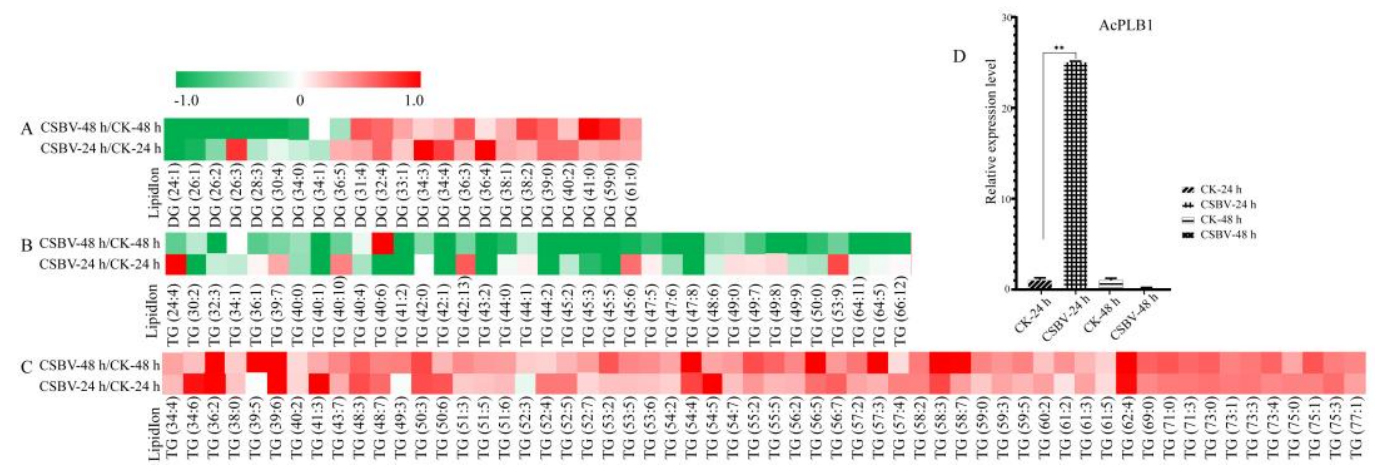

Figure 5. Lipid species of DG and TG were more induced during the CSBV infection process. (A) Heatmap showing the DG change of both CSBV_24 h vs. CK_24 h and CSBV_48 h vs. CK_48 h; (B) heatmap showing the down-regulation of TG in CSBV_24 h vs. CK_24 h or CSBV_48 h vs. CK_48 h; (C) hatmap showing the up-regulation of TG in both CSBV_24 h vs. CK_24 h and CSBV_48 h vs. CK_48 h; (D) the expression levels of phospholipidase B1 post infection of CSBV and control by quantitative real-time PCR. ${ }^{* *}$ indicates $p$-value of $<0.01$.

\subsection{Alterations in Phospholipids Homeostasis during CSBV Infection}

Besides the GPs, phospholipids including PA, PC, PE, PS, PI, PG, LPC, LPG and OAHFA were identified in higher abundance in the CSBV versus healthy larvae. Selected PC species were up-regulated at both time points (Figure 6). Interestingly, the majority of PC species that were up-regulated had unsaturated fatty acyl chains. Of the PC lipids identified in this study, almost all were increased in CSBV-infected larvae, including 15 with a $p<0.05$. The only statistically significant PC lipid that was decreased was PC $(14: 0 / 22: 2)(p$-value $=0.01)$ (Figure 6). A significant increase in PC is associated with viral replication [31]. Thus, PC (18:1/14:1) was identified as a characteristic molecule for the group of the infected larvae (Table 2). Analysis of the overall fold-change in PE (Figure 6) showed an increase between the CSBV-infected and control. PE (18:0/18:2) was up-regulated more than 4-fold. Combining PA (38:2) was also up-regulated more than 2-fold; these results indicated that CSBV infection has changed the lipid composition of the host membrane.

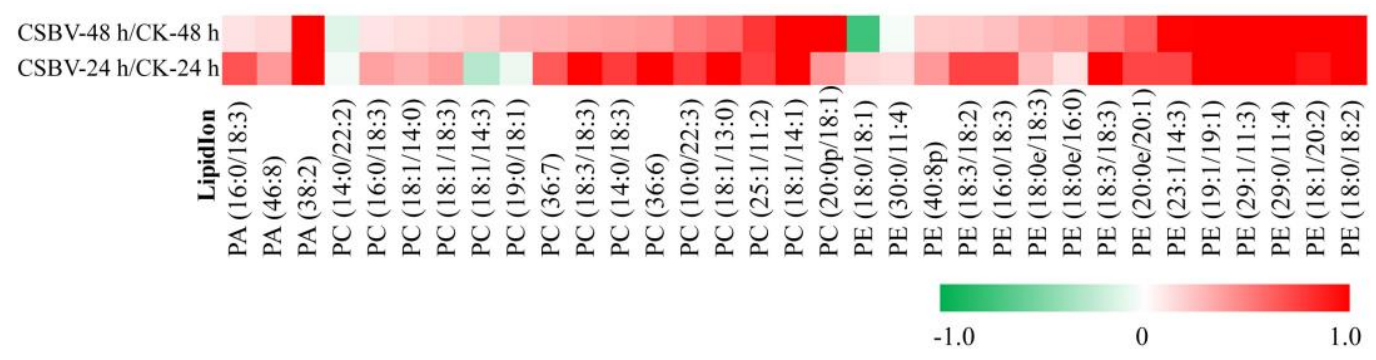

Figure 6. Heatmap of Log2 fold changes in phospholipids species following CSBV infection of A. c. cerana larvae on $p . i$. $24 \mathrm{~h}$ and $p$. i. $48 \mathrm{~h}$ arranged by putative ID subclasses.

PC synthesis is significantly up-regulated by many viral infections, including brome mosaic virus (BMV) [31], Flock House virus (FHV) [32], DENV [20] and poliovirus [33]. Consistent with previous reports, increased levels of PC were identified in CSBV-infected larvae. In addition, PE can be synthesized either by reactions analogous to those of de novo synthesis of PC or by decarboxylation of PS. Furthermore, PE was redistributed to the TBSV replication sites by protein p33 [34]. The increased PEs identified in CSBV-infected larva may contribute to the replication of CSBV. 
Table 2. Lipid markers detected by Principal Component Analysis from the CSBV-infected larvae.

\begin{tabular}{|c|c|c|c|c|c|c|c|c|c|c|}
\hline Significant Lipids & $\begin{array}{c}\text { Theoretical } \\
\text { Mass }\end{array}$ & $\begin{array}{l}\text { Trend in } \\
\text { CSBV vs. } \\
\text { Control }\end{array}$ & $\begin{array}{c}\text { Detection } \\
\text { Mode }\end{array}$ & $\begin{array}{l}\text { Lipid } \\
\text { Class }\end{array}$ & $\begin{array}{c}\log 2(\mathrm{FC}) \\
\text { aCSBV_24 h } \\
\text { vs. CK_24 h) }\end{array}$ & $\begin{array}{c}\text { Pvalue } \\
\text { (CSBV_24 h } \\
\text { vs. CK_25 h) }\end{array}$ & $\begin{array}{c}\text { VIP } \\
(\mathrm{CSBV} 224 \mathrm{~h} \\
\text { vs. CK_24 h) }\end{array}$ & $\begin{array}{l}\log 2(\mathrm{FC}) \text { a } \\
\left(\mathrm{CSBV} \_48 \mathrm{~h}\right. \\
\text { vs. CK_48 h) }\end{array}$ & $\begin{array}{c}\text { Pvalue } \\
\left(\mathrm{CSBV} \_48 \mathrm{~h}\right. \\
\text { vs. CK_48 h) }\end{array}$ & $\begin{array}{c}\text { VIP } \\
(\mathrm{CSBV} 448 \mathrm{~h} \\
\text { vs. CK_48 h) }\end{array}$ \\
\hline Cer $(\mathrm{d} 14: 1+\mathrm{hO} / 21: 0+\mathrm{O})$ & 601.551 & $\mathrm{Up}$ & pos & Cer & 1.282 & 0.012 & 2.067 & 1.674 & 0.020 & 1.770 \\
\hline Cer $(\mathrm{d} 20: 1)$ & 359.326 & Up & pos & Cer & 0.931 & NS & 0.250 & 3.093 & 0.043 & 1.656 \\
\hline $\operatorname{Cer}(\mathrm{d} 40: 1+\mathrm{hO}+\mathrm{O})$ & 652.588 & Up & neg & Cer & 0.789 & NS & 0.796 & 2.642 & 0.046 & 1.642 \\
\hline DG $(41: 0 e)$ & 703.657 & Up & pos & DG & 1.251 & 0.011 & 2.071 & 2.252 & 0.0001 & 1.989 \\
\hline MG $(36: 1)$ & 631.563 & Up & pos & MG & 1.607 & NS & 1.698 & 2.281 & 0.004 & 1.904 \\
\hline PC (18:1/14:1) & 774.529 & Up & pos & PC & 2.735 & 0.036 & 1.915 & 2.100 & NS & 1.138 \\
\hline PE (18:0/18:2) & 744.553 & Up & pos & PE & 4.856 & 0.017 & 2.026 & 17.333 & NS & 0.987 \\
\hline PE (18:0e/18:3) & 726.544 & Up & neg & PE & 1.200 & 0.044 & 1.873 & 1.270 & 0.006 & 1.872 \\
\hline PE (29:0/11:4) & 802.593 & Up & pos & PE & 2.379 & 0.017 & 2.028 & 7.548 & NS & 1.057 \\
\hline $\mathrm{SM}(\mathrm{d} 20: 0 / 19: 1)$ & 817.644 & Up & pos & $\mathrm{SM}$ & 1.572 & 0.024 & 1.980 & 1.455 & 0.006 & 1.873 \\
\hline $\mathrm{SM}(\mathrm{d} 37: 1)$ & 745.621 & Up & pos & SM & 1.613 & 0.032 & 1.933 & 1.685 & 0.019 & 1.776 \\
\hline $\mathrm{SM}(\mathrm{d} 41: 2)$ & 799.668 & Up & pos & SM & 2.641 & NS & 1.298 & 4.188 & 0.0317 & 1.708 \\
\hline TG (16:0/18:1/18:3) & 872.770 & Up & pos & TG & 1.447 & 0.009 & 2.0974 & 1.133 & 0.028 & 1.729 \\
\hline TG $(18: 1 / 18: 1 / 18: 3)$ & 898.785 & $\mathrm{Up}$ & pos & TG & 2.289 & 0.011 & 2.078 & 1.276 & NS & 1.006 \\
\hline TG $(24: 4)$ & 485.287 & Up & pos & TG & 2.307 & 0.029 & 1.953 & 0.651 & NS & 0.897 \\
\hline TG (39:6) & 675.517 & Up & pos & TG & 10.899 & 0.049 & 1.848 & 23.588 & NS & 0.988 \\
\hline TG $(43: 7)$ & 729.563 & $\mathrm{Up}$ & pos & TG & 1.251 & 0.031 & 1.943 & 1.383 & 0.015 & 1.804 \\
\hline OAHFA $(16: 0 / 26: 0)$ & 649.614 & Down & neg & FA & 1.361 & NS & 1.341 & 1.589 & 0.008 & 1.856 \\
\hline OAHFA (16:0/28:0) & 677.645 & Down & neg & FA & 1.257 & NS & 1.354 & 1.617 & 0.007 & 1.863 \\
\hline OAHFA $(18: 1 / 26: 0)$ & 675.629 & Down & neg & FA & 1.433 & NS & 1.409 & 1.673 & 0.002 & 1.926 \\
\hline
\end{tabular}

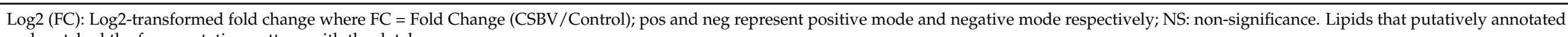
and matched the fragmentation pattern with the database. 


\subsection{CSBV Infection Causes an Accumulation of Sphingolipids}

Sphingolipids have many biological functions that regulate cell death, growth, differentiation and intracellular trafficking and are critical in microbial pathogenesis [35,36]. De novo synthesis of SPs occurs in the endoplasmic reticulum through the condensation of L-serine and palmitoyl-CoA to form ceramide (Cer) via several intermediates (Figure 7A). The primary sphingolipids regulated during CSBV infection were sphingomyelin (SM) and ceramide (Cer). More recently, sphingolipids and their metabolizing enzymes were implicated in regulating the interactions between bacterial or viral pathogens and plants or animals [37]. A study has reported that HCV increases sphingolipids levels in infected host cells [38]. It has been further demonstrated that the increased Cer and SM are required for WNV replication [39]. Inhibition of Serine palmitoyltransferase (SPT), the first-step enzyme in Cer biosynthesis, suppressed HCV replication [40,41]. Several viruses such as measles virus, rhinovirus (RV) and DENV [42] activated sphingomyelinase (SMase), which is responsible for the degradation of SM and synthesis of Cer. Sphingomyelin synthase (SMS) is also required for HIV-mediated membrane fusion by co-localizing with the HIV receptor in the plasma membrane [43]. Our study identified 492 species of sphingolipids in A. c. cerana with 62 species that were altered upon CSBV-infection. Cer (d20:1), Cer (d17:0/16:0) and SM (d41:2) were up-regulated in CSBV-infected larvae by $>2$-fold compared to the control (Figure 8, Table 2). Similarly, SM was also up-regulated in CSBV-infected larvae.

To investigate the relative expression levels of the nine genes encoding sphingolipidmetabolizing enzymes in different CSBV infection stages, qPCR assays were performed using specific primers (Table 1). When comparing CSBV-infected A.c. cerana larvae with CSBV-free larvae, six genes (AcCS5, AcCeramidase, AcSMPD, AcSMPD1, AcSMPD4 and AcGSC) were more highly expressed at $24 \mathrm{~h}$ post-infection (Figure $7 \mathrm{~B}$ ), suggesting that the increase in Cer during the early infection is possibly due to both de novo synthesis and SM degradation. After $48 \mathrm{~h} \mathrm{CSBV}$ infection, AcCS5 was continuously increased (Figure 7B), and AcSMase showed a 6-fold higher transcription level than control (6-fold, $p=0.02)$. In addition, AcSPT1 was more highly expressed $(p=0.002)$, while AcGSC4 decreased. RNA-dependent RNA polymerase (RdRp) of CSBV contains a helix-turn-helix sphingolipid-binding motif in its finger domain. All these data indicate that CSBV may use Cer and SM for replication. However, the exact mechanism of CSBV replication remains unknown and requires further studies.

\subsection{Biomarkers Screening of the CSBV-Infected Larvae}

Based on the criteria of $p$-value $<0.05$ and | Log2 fold change $\mid>1$ and VIP $>1.5$ for the identification of potential biomarkers, OPLSDA analysis detected several potential biomarkers of CSBV infection, as indicated in Table 2. A total of 20 significantly changed lipids were identified when the two groups of samples were compared in pairs. These lipids included those belonging to the phospholipid, glycerolipid and sphingolipid categories. Notably, Cer (d14:1 + hO/21:0 + O), DG (41:0e), PE (18:0e/18:3), SM (d20:0/19:1), SM (d37:1), TG (16:0/18:1/18:3), TG (18:1/20:4/21:0) and TG (43:7) were significantly changed in both CSBV_24 $\mathrm{h}$ vs. CK_24 $\mathrm{h}$ and CSBV_48 $\mathrm{h}$ vs. CK_48 h. Furthermore, TG (39:6) was increased by $>10$ fold and can be used as a biomarker for early detection of CSD. Fatty acids can be incorporated into complex lipids such as lycerophospholipids and glycerolipids that have structural roles in membranes. In this study, 15 OAHFA were detected, of which three had lower abundances in larvae at $48 \mathrm{~h}$ post-infection compared to uninfected controls (Table S1). OAHFA is a unique type of ULCFA that constitutes the fatty acyl moiety in Cer, as reported in mice with fatty acid transport protein 4 (FATP4) mutations [44]. 


\subsection{Pathway Analysis of CSBV-Infected A. c. cerana larvae}

Based on the list of significantly up-regulated lipids after CSBV-infection, MetaboAnalyst (http:/ / www.metaboanalyst.ca, accessed on 11 November 2019) was applied to investigate the pathways that were markedly perturbed. As shown in Figure 9, upon CSBV infection, pathways related to glycerophospholipid metabolism, glycosylphosphatidylinositol (GPI) -anchor biosynthesis, glycerolipid metabolism, arachidonic acid metabolism and alpha-linolenic acid metabolism were found to be significantly affected. Pathway impact results indicate that the glycerophospholipid metabolism pathways presented a higher impact than the other pathways. Therefore, we speculated that the disorder of phospholipids metabolism may be associated with CSBV entry.

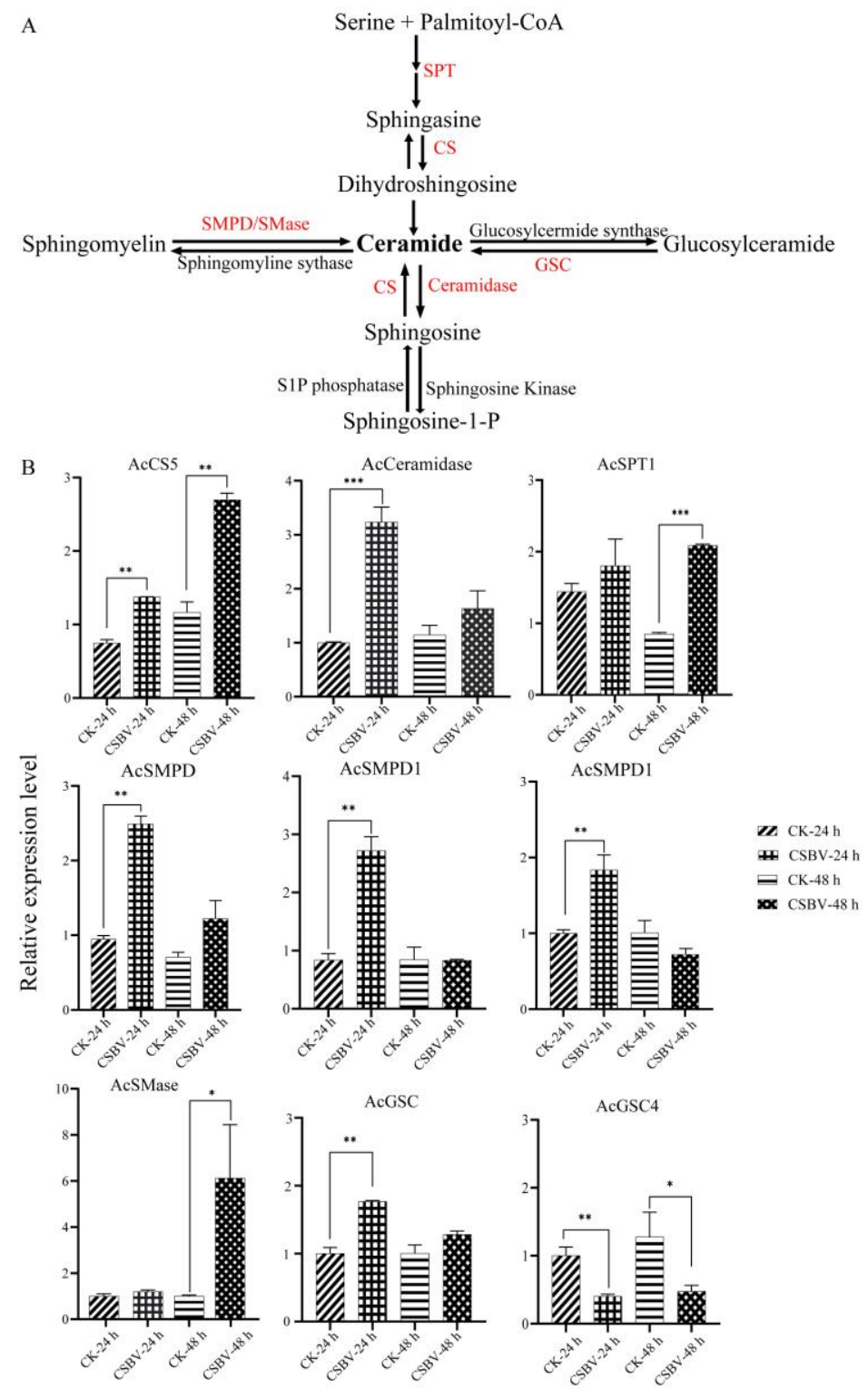

Figure 7. The pathway of sphingolipid metabolism (A) and the expression levels of 9 sphingolipid enzymes upon CSBV infection by quantitative real-time PCR (B). The enzymes analyzed in this study are in red and full names are listed in Table 1. Data are shown as means \pm SE. Asterisks $\left(^{*}\right)$ indicates statistically significant $p$-value of $<0.05,{ }^{* *} p$-value of $<0.01,{ }^{* * *} p$-value of $<0.001$. 

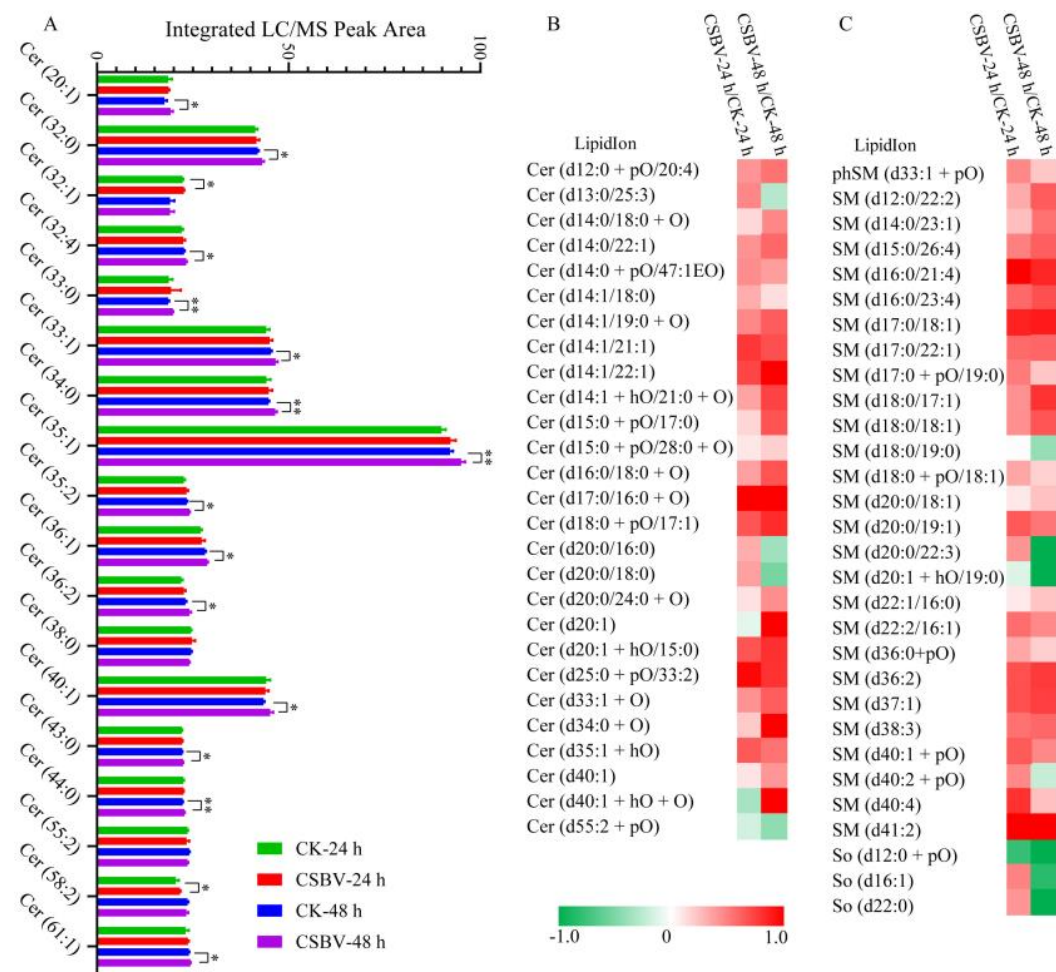

Figure 8. Ceramide and sphingomyelin were regulated under CSBV infection. (A) The total relative content of ceramide (Cer) detected in CSBV-infection groups and healthy larvae. (B) and (C) are heatmaps of Log2 fold changes of ceramide (Cer) and sphingomyelin (SM) species, respectively. Asterisks $\left({ }^{*}\right)$ indicates statistically significant $p$-value of $<0.05,{ }^{* *} p$-value of $<0.01$.

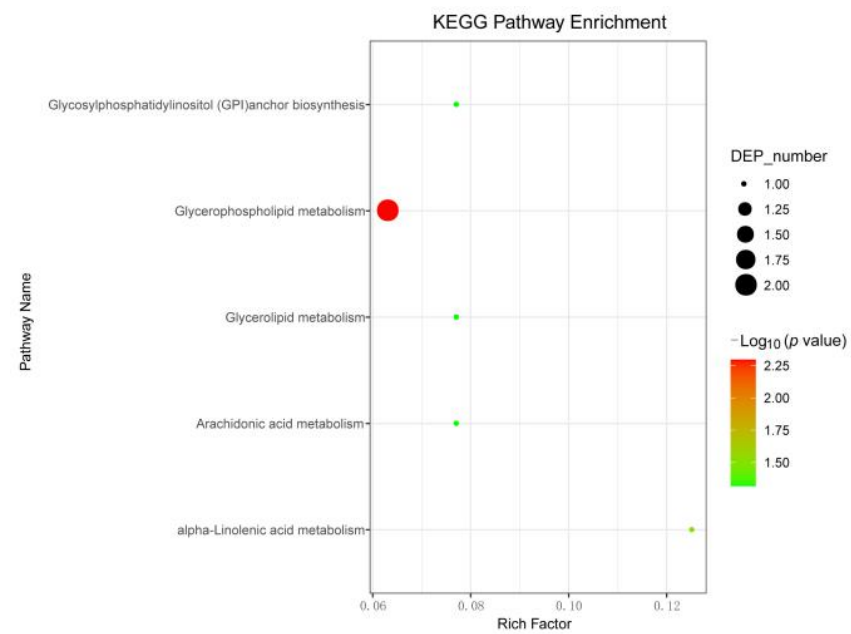

Figure 9. Pathway analysis associated with CSBV infection was carried out by MetaboAnalyst. The $Y$-axis, " $\log 10(p)$ ", represented the transformation of the original $p$-value calculated from the enrichment analysis. The $X$-axis represents the pathway impact value calculated from the pathway topology analysis, and larger bubbles represent higher pathway impact values.

\section{Conclusions}

CSD is a viral disease of $A$. c. cerana larvae. One of its typical symptoms is the formation of a "sac" with ecdysial fluid accumulation. Thus, metabolic disorders of the host caused by CSBV infection provide insight into the phenomenon of the 'sac'. The lipidome analysis of honeybee larva after CSBV infection in this study demonstrates the complex response patterns in the whole animal. A total of 266 lipids, including categories 
of DG, TG, PC, PE, SM and Cer, were significantly altered upon CSBV infection. The level of TGs was found to be significantly increased in CSBV infection. Furthermore, TG (39:6) of CSBV_24 $\mathrm{h}$ increased by more than 10 fold compared to CK_24 $\mathrm{h}$ and may be used as a biomarker for early detection of CSD. Given that AcPLB1 was up-regulated, CSBV infection causes a higher level of lipolysis. The precise role of the increased TG accumulation needs to be explored. Importantly, marked elevation of sphingolipids levels was coincident with the expression levels of eight sphingolipid enzymes upon CSBV infection. Based on these findings, the next steps will be to investigate the mechanisms by which these lipid species play a role in CSBV replication, as well as their potential use as therapeutic targets for CSBV infection.

Supplementary Materials: The following is available online at https://www.mdpi.com/article/10.3 390/insects12080703/s1, Table S1: lipids species identified in healthy larva vs. CSBV-infected larva at different time points.

Author Contributions: Methodology, X.L. and Y.L.; software, J.X.; validation, X.F.; formal analysis, Z.M. and L.W.; investigation, X.L. and D.H.; resources, C.W.; data curation, Y.L.; writing—original draft preparation, X.D.; writing—review and editing, X.D.; visualization, Z.L.; supervision, Z.Z.; project administration, Z.Z.; funding acquisition, X.D., Z.Z. and J.X. All authors have read and agreed to the published version of the manuscript.

Funding: Research reported here was supported by the Natural Science Foundation of Chongqing (No. cstc2019jcyj-msxmX0564), the Earmarked Fund for China Agriculture Research System (No. CARS-44), the National Natural Science Foundation of China (No. 31770160), the Scientific and Technological Research Program of Chongqing Municipal Education Commission (No. KJQN202000521, No. KJQN201900516), the Scientific Research Starting Foundation for the Returned Scholars, Chongqing (No. cx2019137) and the fund of creation and research team in college and universities of Chongqing Municipal Education Commission (No. CXQT21013).

Institutional Review Board Statement: Not applicable.

Data Availability Statement: All lipids species data are available in the Supplementary Materials (Table S1). The morphology of larvae and qRT-PCR data are available via contact to corresponding author.

Acknowledgments: We thank Shanghai Hoogen Biotechnology Co., Ltd. for technical assistance.

Conflicts of Interest: The authors declare no conflict of interest.

\section{References}

1. Liu, P.; Wu, J.; Li, H. Economic value assessment of agricultural bee pollination in China. Sci. Agric. Sin. 2012, 44, 5117-5123.

2. Ongus, J.R.; Peters, D.; Bonmatin, J.M.; Bengsch, E.; Vlak, J.M.; van Oers, M.M. Complete sequence of a picorna-like virus of the genus Iflavirus replicating in the mite Varroa destructor. J. Gen. Virol. 2004, 85, 3747-3755. [CrossRef] [PubMed]

3. Tentcheva, D.; Gauthier, L.; Zappulla, N.; Dainat, B.; Cousserans, F.; Colin, M.E.; Max, B. Prevalence and seasonal variations of six bee viruses in Apis mellifera L. and Varroa destructor mite populations in France. Appl. Environ. Microbiol. 2004, 70, 7185-7191. [CrossRef]

4. Bailey, L. The multiplication and spread of sacbrood virus of bees. Ann. Appl. Biol. 1969, 63, 483-491. [CrossRef] [PubMed]

5. Bailey, L.; Gibbs, A.J.; Woods, R.D. Sacbrood Virus of the Larval Honey Bee (Apis Mellifera Linnaeus). Virology 1964, 23, 425-429. [CrossRef]

6. Zhang, G.Z.; Han, R.C. Advances on Sacbrood of Honeybees. Chin. J. Biol. Control. 2008, 24, 130-137. (In Chinese)

7. Ma, M.X.; Ma, C.; Li, M.; Wang, S.Q.; Yang, S.; Wang, S.D. Loop-mediated isothermal amplification for rapid detection of Chinese sacbrood virus. J. Virol. Methods 2011, 176, 115-119. [CrossRef] [PubMed]

8. Li, J.L.; Qin, H.R.; Wu, J.; Sadd, B.M.; Wang, X.H.; Evans, J.D.; Peng, W.J.; Chen, Y.P. The prevalence of parasites and pathogens in Asian honeybees Apis cerana in China. PLoS ONE 2012, 7, e47955. [CrossRef]

9. Yan, X.; Han, R.C. Diagnostic technologies of common pathogens of honeybees in China. Chin. Bull. Entomol. 2008, 45, 483-488.

10. Ghosh, R.C.; Ball, B.V.; Willcocks, M.M. The nucleotide sequence of sacbrood virus of the honey bee: An insect picorna-like virus. J. Gen. Virol. 1999, 80, 1541-1549. [CrossRef]

11. Skubnik, K.; Novacek, J.; Fuzik, T.; Pridal, A.; Paxton, R.J.; Plevka, P. Structure of deformed wing virus, a major honey bee pathogen. Proc. Natl. Acad. Sci. USA 2017, 114, 3210-3215. [CrossRef] 
12. De Miranda, J.R.; Dainat, B.; Locke, B.; Cordoni, G.; Berthoud, H.; Gauthier, L.; Neumann, P.; Budge, G.E.; Ball, B.V.; Stoltz, D.B. Genetic characterization of slow bee paralysis virus of the honeybee (Apis mellifera L.). J. Gen. Virol. 2010, 91, 2524-2530. [CrossRef] [PubMed]

13. Zhang, J.; Feng, J.; Liang, Y.; Chen, D.; Zhou, Z.H.; Zhang, Q.; Lu, X. Three-dimensional structure of the Chinese Sacbrood bee virus. Sci. China C Life Sci. 2001, 44, 443-448. [CrossRef] [PubMed]

14. Prochazkova, M.; Fuzik, T.; Skubnik, K.; Moravcova, J.; Ubiparip, Z.; Pridal, A.; Plevka, P. Virion structure and genome delivery mechanism of sacbrood honeybee virus. Proc. Natl. Acad. Sci. USA 2018, 115, 7759-7764. [CrossRef]

15. Zhang, Z.; He, G.; Filipowicz, N.A.; Randall, G.; Belov, G.A.; Kopek, B.G.; Wang, X. Host Lipids in Positive-Strand RNA Virus Genome Replication. Front. Microbiol. 2019, 10, 286. [CrossRef] [PubMed]

16. Villareal, V.A.; Rodgers, M.A.; Costello, D.A.; Yang, P.L. Targeting host lipid synthesis and metabolism to inhibit dengue and hepatitis C viruses. Antiviral. Res. 2015, 124, 110-121. [CrossRef] [PubMed]

17. Hofmann, S.; Krajewski, M.; Scherer, C.; Scholz, V.; Mordhorst, V.; Truschow, P.; Schobel, A.; Reimer, R.; Schwudke, D.; Herker, E. Complex lipid metabolic remodeling is required for efficient hepatitis C virus replication. Biochim. Biophys. Acta Mol. Cell Biol. Lipids 2018, 1863, 1041-1056. [CrossRef] [PubMed]

18. Nguyen, A.; Guedan, A.; Mousnier, A.; Swieboda, D.; Zhang, Q.; Horkai, D.; Le Novere, N.; Solari, R.; Wakelam, M.J.O. Host lipidome analysis during rhinovirus replication in HBECs identifies potential therapeutic targets. J. Lipid Res. 2018, 59, 1671-1684. [CrossRef]

19. Queiroz, A.; Pinto, I.F.D.; Lima, M.; Giovanetti, M.; de Jesus, J.G.; Xavier, J.; Barreto, F.K.; Canuto, G.A.B.; do Amaral, H.R.; de Filippis, A.M.B.; et al. Lipidomic analysis reveals serum alteration of plasmalogens in patients infected with ZIKA Virus. Front. Microbiol. 2019, 10, 753. [CrossRef]

20. Chotiwan, N.; Andre, B.G.; Sanchez-Vargas, I.; Islam, M.N.; Grabowski, J.M.; Hopf-Jannasch, A.; Gough, E.; Nakayasu, E.; Blair, C.D.; Belisle, J.T.; et al. Dynamic remodeling of lipids coincides with dengue virus replication in the midgut of Aedes aegypti mosquitoes. PLoS Pathog. 2018, 14, e1006853. [CrossRef]

21. Perera, R.; Riley, C.; Isaac, G.; Hopf-Jannasch, A.S.; Moore, R.J.; Weitz, K.W.; Pasa-Tolic, L.; Metz, T.O.; Adamec, J.; Kuhn, R.J. Dengue virus infection perturbs lipid homeostasis in infected mosquito cells. PLoS Pathog. 2012, 8, e1002584. [CrossRef]

22. Feng, J.X.; Zhang, Q.Z.; Ma, Z.W.; Zhang, J.Q.; Huang, W.Z.; Zhang, X.F. Purification, crystallization and structure of the Chinese Sacbrood virus. J. Chin. Electron. Microsc. Soc. 1998, 17, 387-388.

23. Schmeh, D.R.; Tomé, H.V.V.; Mortensen, A.N.; Martins, G.F.; Ellis, J.D. Protocol for the in vitro rearing of honey bee (Apis mellifera L.) workers. J. Apicult. Res. 2016, 55, 113-129. [CrossRef]

24. Lin, Y.H.; Chen, Y.C.; Kao, T.Y.; Lin, Y.C.; Hsu, T.E.; Wu, Y.C.; Ja, W.W.; Brummel, T.J.; Kapahi, P.; Yuh, C.H.; et al. Diacylglycerol lipase regulates lifespan and oxidative stress response by inversely modulating TOR signaling in Drosophila and C. elegans. Aging Cell 2014, 13, 755-764. [CrossRef] [PubMed]

25. Merida, I.; Avila-Flores, A.; Merino, E. Diacylglycerol kinases: At the hub of cell signalling. Biochem. J. 2008, 409, 1-18. [CrossRef]

26. Pennington, J.E.; Nussenzveig, R.H.; Van Heusden, M.C. Lipid transfer from insect fat body to lipophorin: Comparison between a mosquito triacylglycerol-rich lipophorin and a sphinx moth diacylglycerol-rich lipophorin. J. Lipid Res. 1996, 37, 1144-1152. [CrossRef]

27. Cheon, H.M.; Shin, S.W.; Bian, G.; Park, J.H.; Raikhel, A.S. Regulation of lipid metabolism genes, lipid carrier protein lipophorin, and its receptor during immune challenge in the mosquito Aedes aegypti. J. Biol. Chem. 2006, 281, 8426-8435. [CrossRef] [PubMed]

28. Cheung, W.; Gill, M.; Esposito, A.; Kaminski, C.F.; Courousse, N.; Chwetzoff, S.; Trugnan, G.; Keshavan, N.; Lever, A.; Desselberger, U. Rotaviruses associate with cellular lipid droplet components to replicate in viroplasms, and compounds disrupting or blocking lipid droplets inhibit viroplasm formation and viral replication. J. Virol. 2010, 84, 6782-6798. [CrossRef]

29. Miyanari, Y.; Atsuzawa, K.; Usuda, N.; Watashi, K.; Hishiki, T.; Zayas, M.; Bartenschlager, R.; Wakita, T.; Hijikata, M.; Shimotohno, K. The lipid droplet is an important organelle for hepatitis C virus production. Nat. Cell Biol. 2007, 9, $1089-1097$. [CrossRef]

30. Gondim, K.C.; Atella, G.C.; Pontes, E.G.; Majerowicz, D. Lipid metabolism in insect disease vectors. Insect. Biochem. Mol. Biol. 2018, 101, 108-123. [CrossRef]

31. Zhang, J.; Zhang, Z.; Chukkapalli, V.; Nchoutmboube, J.A.; Li, J.; Randall, G.; Belov, G.; Wang, X. Positive-strand RNA viruses stimulate host phosphatidylcholine synthesis at viral replication sites. Proc. Natl. Acad. Sci. USA 2016, 113, E1064-E1073.

32. Castorena, K.M.; Stapleford, K.A.; Miller, D.J. Complementary transcriptomic, lipidomic, and targeted functional genetic analyses in cultured Drosophila cells highlight the role of glycerophospholipid metabolism in Flock House virus RNA replication. BMC Genom. 2010, 11, 183.

33. Nchoutmboube, J.A.; Viktorova, E.G.; Scott, A.J.; Ford, L.A.; Pei, Z.; Watkins, P.A.; Ernst, R.K.; Belov, G.A. Increased long chain acyl-Coa synthetase activity and fatty acid import is linked to membrane synthesis for development of picornavirus replication organelles. PLoS Pathog. 2013, 9, e1003401.

34. Xu, K.; Nagy, P.D. RNA virus replication depends on enrichment of phosphatidylethanolamine at replication sites in subcellular membranes. Proc. Natl. Acad. Sci. USA 2015, 112, E1782-E1791.

35. Hannun, Y.A.; Obeid, L.M. Principles of bioactive lipid signalling: Lessons from sphingolipids. Nat. Rev. Mol. Cell Biol. 2008, 9 , 139-150. [PubMed]

36. Schneider-Schaulies, J.; Schneider-Schaulies, S. Viral infections and sphingolipids. Handb. Exp. Pharmacol. 2013, 216, 321-340. 
37. Heung, L.J.; Luberto, C.; Del Poeta, M. Role of sphingolipids in microbial pathogenesis. Infect. Immun. 2006, 74, $28-39$.

38. Hirata, Y.; Ikeda, K.; Sudoh, M.; Tokunaga, Y.; Suzuki, A.; Weng, L.; Ohta, M.; Tobita, Y.; Okano, K.; Ozeki, K.; et al. SelfEnhancement of Hepatitis C Virus Replication by Promotion of Specific Sphingolipid Biosynthesis. PLoS Pathog. 2012, 8, e1002860.

39. Aktepe, T.E.; Pham, H.; Mackenzie, J.M. Differential utilisation of ceramide during replication of the flaviviruses West Nile and dengue virus. Virology 2015, 484, 241-250. [PubMed]

40. Umehara, T.; Sudoh, M.; Yasui, F.; Matsuda, C.; Hayashi, Y.; Chayama, K.; Kohara, M. Serine palmitoyltransferase inhibitor suppresses HCV replication in a mouse model. Biochem. Biophys. Res. Commun. 2006, 346, 67-73. [PubMed]

41. Katsume, A.; Tokunaga, Y.; Hirata, Y.; Munakata, T.; Saito, M.; Hitohisa, H.; Okamoto, K.; Ohmori, Y.; Kusanagi, I.; Fujiwara, S.; et al. A serine palmitoyltransferase inhibitor blocks hepatitis C virus replication in human hepatocytes. Gastroenterology 2013, 145, 865-873. [CrossRef] [PubMed]

42. Schneider-Schaulies, J.; Schneider-Schaulies, S. Sphingolipids in viral infection. Biol. Chem. 2015, 396, 585-595. [CrossRef] [PubMed]

43. Hayashi, Y.; Nemoto-Sasaki, Y.; Tanikawa, T.; Oka, S.; Tsuchiya, K.; Zama, K.; Mitsutake, S.; Sugiura, T.; Yamashita, A. Sphingomyelin synthase 2, but not sphingomyelin synthase 1, is involved in HIV-1 envelope-mediated membrane fusion. J. Biol. Chem. 2014, 289, 30842-30856. [CrossRef]

44. Lin, M.H.; Hsu, F.F.; Crumrine, D.; Meyer, J.; Elias, P.M.; Miner, J.H. Fatty acid transport protein 4 is required for incorporation of saturated ultralong-chain fatty acids into epidermal ceramides and monoacylglycerols. Sci. Rep. 2019, 9, 13254. [CrossRef] [PubMed] 